\title{
Stradivarius Violins: Chemical Analysis of Wood
}

DOI: $10.1134 / \mathrm{S} 1061934808020019$

Attempts at understanding how well-known Cremona violin makers of the 17 th-18th centuries could achieve such seductive voices of their strings have been made for a long time. Numerous factors, including the shape of the instrument, the thickness of the wooden plates, the coatings on wood, etc., have been considered. Now, wood is being studied by two nondestructive methods $[1,2]$, solid-state ${ }^{13} \mathrm{C}$ nuclear magnetic resonance and Fourier transform IR spectrometry; the latter method has been applied in two versions, e.g., frustrated total internal reflection and diffuse reflection.

It is usually believed that the secrets of speech violins and altos by Antonio Stradivari and Guarneri del Gesu can be found in their exceptional skills. However, J. Nagyvary, a chemist from Texas asserted in 1978 that, in his opinion, a more important factor is the quality of the materials used by violin makers. These materials were not pretreated by the masters in themselves. Together with a number of colleagues, Nagyvary tried to prove this statement in subsequent studies. It was found that the spectra of wood (a maple from Bosnia) from which the strings of the Cremona masters, first of all violins, were made are indicative of the chemical treatment of wood. These spectra differ from the spectra of materials from which ancient instruments of other European masters living in the same centuries were made. However, European masters usually used the same wood from Bosnia. In addition, IR spectra in the region of the vibrations of carbonyl groups, from 1730 to $1650 \mathrm{~cm}^{-1}$ and at $1237 \mathrm{~cm}^{-1}$, differed from the spectra of the Bosnian maple.

These and other experiments have led researchers to the assumption that a pharmaceutical chemist lived in Cremona who subjected wood to chemical treatment, probably, to protect it from wood borer and a mold. He supplied the materials obtained to manufacturers of furniture, musical instruments, and other workers. It was shown that the wood of some exemplars of furniture made in these years bears the signs of intensive chemical treatment. Most likely, this included boiling in a solution of a number of inorganic substances. In particular, lignin transformations could take place. It is believed that the violin makers did not know the composition used by the pharmacist to treat the wood. They could not reveal the secret of making violins to the next generations. It was simply their good luck.

\section{REFERENCES}

1. Nagyvary, J. et al., Nature, 2006, vol. 444, p. 565.

2. Mukhopadhyay, R., Anal. Chem., 2007, vol. 79, no. 3, p. 819.

Yu. A. Zolotov 